\title{
Research on the Interactive Interpreting Teaching Mode under the Multimedia and Traditional Microteaching Environment
}

\author{
LI Jing \\ Department of Foreign Language and Literature, \\ Huanghuai University, Zhu Ma Dian City, Henan Province.
}

\begin{abstract}
In this paper, we conduct research on the interactive interpreting teaching mode under the multimedia and primary traditional microteaching environment. English interpretation course system construction request from the student reality, on the basis of the actual situation, improving students' comprehensive ability in English interpretation as communicative teaching method in the very great degree to overall effective guide students to practice real interpreting scene comprehensively improve students' intercultural business negotiation, reception and comprehensive ability of the exhibition, and is advantageous to the interpretation of curriculum system construction and the improvement of the students' comprehensive quality. Our research integrates the general principles of the multimedia and primary traditional microteaching environment to form the better paradigm for the education that will enhance the contemporary teaching condition.
\end{abstract}

Keywords- Multimedia, Traditional Microteaching, Interactive Interpreting, Environment.

\section{Introduction}

In today's world of science and technology rapid development, the increasingly frequent international exchanges and cooperation, in the field of international economic competition in the final analysis is talent competition. Under the new historical period, interpreters play a bridge role also increasingly prominent, which means that foreign language talents especially all kinds of interpreters' demand will increase sharply, if we want to continue to expand foreign exchange contact point, contact area, we must be from the strategy of economic development on full understanding urgency of interpretation of talent cultivation. Only in this way can we seize the opportunity and will go the way of power strategy.

Interpretation is the oral or written in the form of oral speech content using another language to convey faithfully. The translation as the two basic forms, there are many things in the common. For example, it is through the translation of communication between two languages. Followed by process to express, namely the translation is information, not language, the main process of understanding and expression, etc. Interpreting is produced with the human language. Its history is much longer than translation history. But as an independent discipline, specialization, functional, professional lag far behind the written translation, so far, the interpreter does not have a complete like translation and advanced translation theory also lack as rich and profound as written translation experience. There are still quite a lot of people don't know what is going on in interpretation, as a teaching material should use what kind of material, what method, what the interpretation class teacher and what should teach students. For higher vocational colleges to be practical and feasible to translate occupational activities oriented education concept to the actual teaching, and select the content easily measurable, cultivation model for higher vocational students, we on select material cannot be divorced from general reality. Interpreting material should combine classroom teaching skills and real interpreting preparation, and alone without background rather than as a section of the material with choice of interpreting course teaching content we will reflect the working process of the integrity and systemic [1-3]. 
Interactive, originally is a social professional academic language. In general, it refers to under the certain social background and the specific situation, individual and individual, individual and group and group and between groups through information dissemination and basic various forms, various properties and various degrees of interaction and influence of the communicative activities. Class as a field of the human life, its shape will inevitably in the interaction between teachers and students as its basic activities. When one of the students in accordance with the requirements of the teachers to make some kind of response at the same time, the student to realize herself in the peer group is bound to be affected by the peer group common emotion, attitude and the mutual relationship, the influence of the exchange ability of its activities and its results. Student's object function is refers to its influence in the process of acquiring knowledge is a teacher of the object, as long as there is access to and use of the knowledge, student's object function is natural. Because in the process of the interactive teaching, in order to complete the transformation of knowledge to the students individual will its main means is to pass knowledge transfer. For solving this issue, traditional microteaching environment is considered to be the proper one for analyzing that could be reflected from the figure one [4].

\section{MICROTEACHING CYCLE}

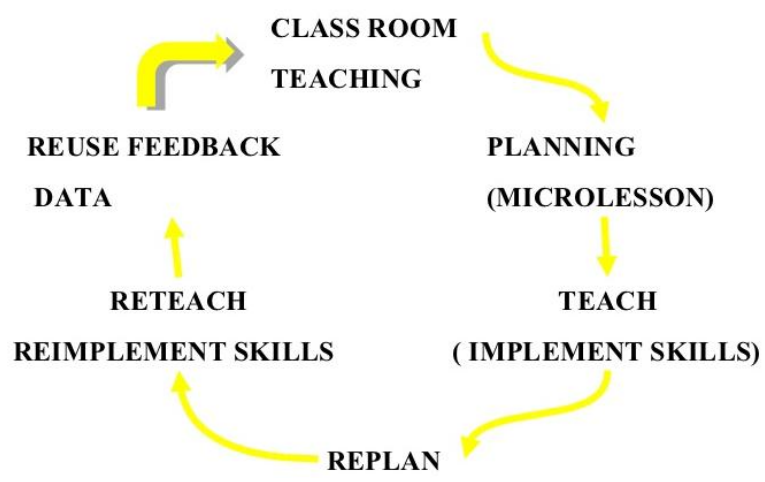

Figure 1. The General Flowchart and Procedures of the Microteaching

In this paper, we conduct research on the interactive interpreting teaching mode under multimedia and traditional microteaching environment. For more the system to make the research of interactive teaching, in-depth and breakthrough, promoted to the theory of consciousness, to lead and guide the teaching reform practice, the author in the main characteristics of the connotation of the interactive teaching from the core angle of sociology, theory support, implementation principle and related policy issues such as do some analysis. In the later sections, we will discuss the issues in detail.

\section{The Proposed Methodology}

The Interactive Teaching Principles. Interactive teaching refers to classroom teachers based on the requirements of the teaching outline, according to the specific requirements of the teaching content, through the careful design of teaching and teaching methods to arouse the enthusiasm of students to participate in teaching activities, encouraging them to "control" into the teaching activities, the vivid and interesting teaching activities in the deep and the comprehensive communication, exchange and mutual learning, deepen the understanding and core knowledge of the teaching content, and make the students' practical ability, independent analysis problem, problem-solving ability and the innovation ability was further strengthened.

To improve and improve higher vocational English interactive teaching strategies, we could follow the listed suggestions. (1) Teaching activities to be the effective activities, activities of the body must have a subject consciousness, the participation consciousness. On the one hand, teachers' initiative to study the teaching material, the careful design class, improving teaching methods; On the other hand, students should also actively participate in classroom activities, questioned the colleague, positive thinking. Each must rectify fault, teachers don't have to take the occasional mistake a tolerant attitude to the student as unconventional or unorthodox ideas as much as possible to give encouragement. (2) 
Today's English teachers should possess profound professional knowledge, strong oral English and communication skills, broad knowledge of world geography and a lot of young English teachers from school to school, the interactive teaching between teachers and students lack of rational cognition and practice of exercise. So, to strengthen professional learning, improve the quality is the top priority. (3) Teachers should with new theoretical accomplishment and vision led the organization form of class teaching, the teaching and learning is fundamental in improving our quality and ability [5-6].

In students' autonomous inquiry activity, based on the development of students, and highlight the student active learning, to fully demonstrate their thinking process and general emotional experience, emphasis on training students' inquiry ability and the innovation consciousness, the implementation under the guidance of teachers, with the all-round development of students to knowledge and ability quality. In this pattern, the student is the subject of basic information processing, knowledge actively constructing as the teachers in the teaching the main task is to guide and help the student autonomous learning, provide them with relevant learning resources, and is no longer in general accordance with the teaching material system to explain the knowledge points.

The Multimedia Teaching. With the rapid development of modern technology and multimedia computer, a slide show, video, audio and video teaching material, physical and electronic media, such as the computer projection into quite a number of modern schools. Advanced audiovisual education equipment brings to the education and the teaching activities of a series of profound changes, to the classroom teaching brings new hope and new life, showed the superiority of the traditional education can't compare with, and the right to use a variety of multimedia teaching means that has become social measure information one of the conditions of a qualified education workers.

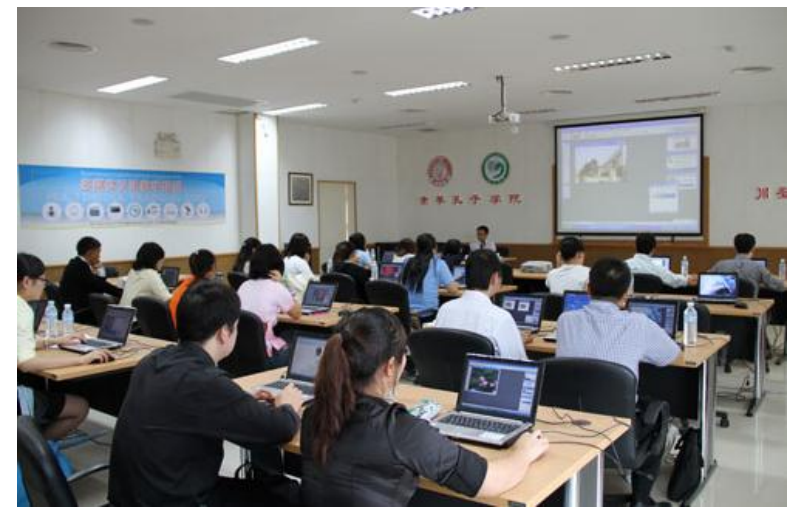

Figure 2. The Demonstration of the Multimedia Teaching Environment

As a teacher, if we can be familiar with the theory of modern teaching means and skills, and can according to the requirements of teaching outline, from the reality of the students choose the modern teaching media, and to that of the reasonable combination of the traditional teaching media that can greatly enrich the classroom teaching, promote students to understand and grasp of knowledge and it also can cultivate the students' various ability, improve student's quality, improve the teaching effect, that play the advantages of the multimedia teaching. However, there are still some challenges that we should take into consideration. (1) The teaching characteristics of higher vocational colleges should highlight the application, target, objective, practical and interactive, courseware should be combining with the characteristics of curriculum and the related content, especially should cooperate with the "work-integrated learning" and curriculum reform that makes every effort to form a variety of forms, content is rich and colorful, lively and informative for the consideration. (2) To deal with a lot of media and the relationship between teachers and students, from the reality of the education teaching, through the analysis of teaching content, selectively uses the multimedia teaching mode, to avoid the use of multimedia teaching content. (3) Teachers in the multimedia 
classroom teaching at the same time to explore or perfect implementation "interactive teaching between teaching and learning", must be good at using body language, oral language, expression language, that pay attention to the students' dynamic, attract students' attention, to have emotional communication with students, to avoid sitting on a platform to read notes from beginning to end, to exert the leading role of teachers [7].

\section{The Microteaching Environment.} Cooperative interaction micro-standard teaching pattern is based on the cooperation as the basis and criterion and the interaction between way and the way to the new teaching mode. It to cooperative learning theory, constructivism learning theory, group dynamics theory, social interdependence theory and other modern education theory as the general instruction, the cooperative learning and interactive learning closely link together, relying on and function on each other and then fuses creation teaching and learning, and coordination between birth, life and living, as mutual learning and mutual assistance, the symbiotic relationship of ecological development.

Under the influence of the behaviorist learning theory, emphasis on the role of teachers, classroom teaching skill training and ignore the human cognitive law in the general learning process, ignore the cognitive subject of trainees, trainees as external stimuli receiver, good teachers teaching experience of memory. Therefore, the teaching skill training is mainly confined to experience imitation, caused in the complex situation of teaching, classroom teaching skills migration is limited by the considerable level, greatly influenced the microteaching training effect. In microteaching practice, in order to make the teaching skill training to achieve the desired effect, except in accordance with theory and steps of the micro-standard teaching, we should also pay attention to the following questions. (1) Take the students as the main body is to make sure it in the micro-standard teaching that is the main part of the practice, is with independent status and potential great teaching practitioners as the whole process of microteaching to their positive consciously to complete with practice. (2) Teaching skills is formed and developed in practice. So pay attention to training is one of the characteristics of microteaching. At present, increasing the proportion of young teachers in the school, its quality will directly relate to the teaching quality of the school. So we must attach great importance to training young teachers, to make them as soon as possible to adapt to the demands of the development of education in teachers colleges to stir up the burden of normal education. (3) Micro-standard teaching should renew the idea to set up the ideas of modern education first, understand and grasp the micro-standard teaching theory, and carry out the importance and necessity of microteaching [8].

The Future of Interpreting Teaching. On the basis of the above literature review, the author thinks that, interpretation practice course is the divided into following three stages, preparation, group respectively independent learning stage and evaluation stage. From preparation to study to evaluate reflection, form a complete learning process, including the main task of the teacher should guide and support the student to carry on the exploration, practice and cooperation, promote students to reflect on, truly outstanding students to learn the main, dominated by ability training. Correspondingly, we summarize the optimized procedures as the follows.

- Interpretation and translation as a translation of two kinds of the practice form, its relevance is self-evident. As if the interpretation is the superstructure, translation is the base. In short, the interpretation is the basis of translation. Before interpreting training or practice, translators should pass. The two parallel not only, and the quality of the former are often in the largely determine the future 
level of interpreting or the size of the potential for development.

- Through the application of the experience type teaching mode, we can see that the main advantage of experiential teaching in the situation of the experience and the actual application, enables students to more fully grasp the learning content and can be applied to practice, not only will learn the language without application.

- Because the student can for refining and summarized preparation materials and opinions, to predict the content of the interpretation, basically achieve simultaneous interpreting ability. In this simulation and the other classmates when neither practical interpretation so nervous, have self-practice too relaxed, relaxation, the basis for poor English major students of vocational colleges is a relatively ideal method of practice [9].

- Experiential teaching requires learners to use the mind and body to experience to feel this way of teaching can not only stimulate students' study enthusiasm pool is beneficial to cultivate the interpersonal communication and cultural exchange.

\section{Conclusion}

In this paper, we conduct research on the interactive interpreting teaching mode under multimedia and traditional microteaching environment and interpreting teaching focus on professional interpreters, imparting interpretation skills and the knowledge, to complete with a specific target communication tasks. Teaching interpreting is a means of foreign language teaching aims to help students to master the language points, improve the level of language, improves language style. In order to distinguish between epistemology and methodology, in view of college English teaching under the background of interpreting teaching and the teaching of interpretation of the status quo of the Chinese characteristics, puts forward the reform of the teaching of interpretation and the interpretation teaching strategy. The diversity of the $21 \mathrm{st}$ century and the characteristics of the global village that has become increasingly apparent, and increasing social demand for translation, especially the interpretation, in order to better meet the needs of the individual and society, China's college English teaching of interpretation and the development of interpreting teaching should get bigger and bigger. In the future, we will combine more related teaching methodologies to form the better modification.

\section{References}

[1] YIN, Hai-ming, and Yuan-wang WEI. "An Interpreting Teaching Model of Software Engineering for Computer Science Students in Colleges and Universities [J]." Journal of Jiaxing University 3 (2013): 029.

[2] Ying, S. O. N. G. "The State of Chunks in Long-term Memory and the Interpreting Quality [J]." Journal of Tianjin Foreign Studies University 3 (2012): 007.

[3] Adler, Jill, and Erlina Ronda. "A framework for describing Mathematics discourse in instruction and interpreting differences in teaching." African Journal of Research in Mathematics, Science and Technology Education 19.3 (2015): 237-254.

[4] Han, J. I. A. N. G. "Reflection on translation and interpreting textbooks for higher vocational education." Journal of Guangzhou University (Social Science Edition) 2 (2012): 013.

[5] Fatkhullova, Kadriya Sungatovna, Radif Rifkatovich Zamaletdinov, and Alfiya Shavketovna Yusupova. "Information-Communicative Devices for Tatar Language Teaching." World Applied Sciences Journal 26.1 (2013): 103-107. 
[6] Plonsky, Luke, and Frederick L. Oswald. "How big is "big"? Interpreting effect sizes in L2 research." Language Learning 64.4 (2014): 878-912.

[7] Zuo, Jia. "Image schemata and visualisation in simultaneous interpreting training." The Interpreter and Translator Trainer 8.2 (2014): 204-216.
[8] Abd-El-Khalick, Fouad. "Teaching with and about nature of science, and science teacher knowledge domains." Science \& Education 22.9 (2013): 2087-2107.

[9] Fey, Marc E., et al. "Is more better? Milieu communication teaching in toddlers with intellectual disabilities." Journal of Speech, Language, and Hearing Research 56.2 (2013): 679-693. 